Guido Vaz Silva

Poder e Decisão em Empresas de Economia de Comunhão:

Dissertação de Mestrado

Dissertação apresentada como requisito parcial para obtenção do título de Mestre pelo Programa de PósGraduação em Administração da PUC-Rio.

Orientador: Sérgio Proença Leitão

Rio de Janeiro

Março de 2008 
Guido Vaz Silva

\title{
Poder e Decisão em Empresas de Economia de Comunhão: \\ Um Estudo de Caso
}

\begin{abstract}
Dissertação apresentada como requisito parcial para obtenção do título de Mestre pelo Programa de PósGraduação em Administração da PUC-Rio. Aprovada pela Comissão Examinadora abaixo assinada.
\end{abstract}

Prof. Sérgio Proença Leitão

Orientador

Departamento de Administração - PUC-Rio

Profa. Patrícia Amélia Tomei Departamento de Administração - PUC-Rio

Profa. Deborah Moraes Zouain EBAPE - FGV

Prof. João Pontes Nogueira

Coordenador(a) Setorial do Centro de Ciências Sociais - PUC-Rio

Rio de Janeiro, 17 de março de 2008. 
Todos os direitos reservados. É proibida a reprodução total ou parcial do trabalho sem autorização da universidade, do autor e do orientador.

Guido Vaz Silva

Graduou-se em Administração de Empresas, na Universidade Federal Fluminense (UFF) em 2006. Atuou por quatro anos na Divisão de Planejamento Estratégico do Instituto Nacional de Câncer (INCA). Atualmente, é pesquisador e desenvolve projetos de extensão, principalmente, nas áreas de engenharia de processos e sistemas de informação pelo Grupo de Produção Integrada (GPI) da Escola Politécnica/COPPE/UFRJ.

Ficha Catalográfica

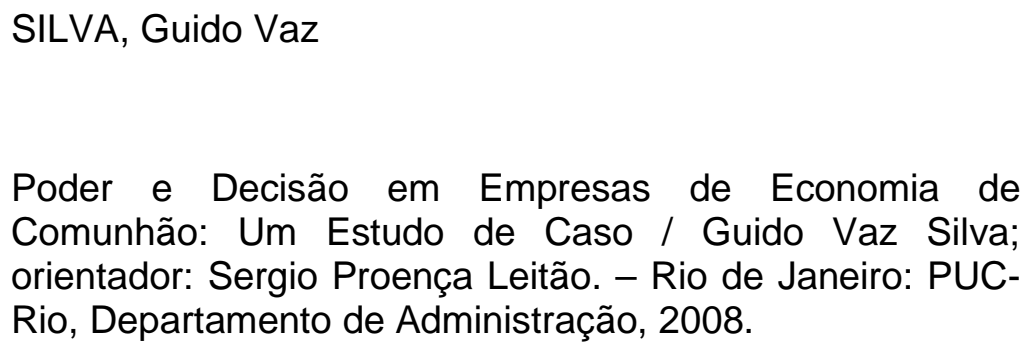

119 f. : il. ; $30 \mathrm{~cm}$

Dissertação (mestrado) - Pontifícia Universidade Católica do Rio de Janeiro, Departamento de Administração.

Inclui bibliografia.

1. Administração - Teses. 2. Poder. 3. Decisão. 4. Economia de Comunhão. I. Leitão, Sergio Proença. II. Pontifícia Universidade Católica do Rio de Janeiro. Departamento de Administração. III. Título 
Aos meus familiares e amigos, pelos momentos e circunstâncias de interação que delinearam minha condição humana. 


\section{Agradecimentos}

Ao Prof. Sergio Proença Leitão, pelo auxílio no caminho tortuoso de feitura deste trabalho, mas, principalmente, por elevar minha referência sobre o real papel de um professor, ou melhor, de um mestre.

Ao meu núcleo familiar, pelo apoio e, principalmente, à minha mãe, Lucia Helena, meu irmão, Enio, e, meu pai, Aridelson, pelo incentivo ao longo do curso. Mesmo que distantes fisicamente, algo nos aproxima todo o tempo.

Aos meus colegas do curso, que tanto em momentos de convergência como de divergência de visões e idéias, possibilitaram-me uma aprendizagem sem precedentes em minha história.

Aos entrevistados da empresa estudada e ao seu proprietário pela solicitude e extrema consideração por minha pessoa quando da minha estadia em sua cidade.

Aos professores que participaram da Comissão Examinadora. 


\section{Resumo}

SILVA, Guido Vaz. Poder e Decisão em Empresas de Economia de Comunhão: Um Estudo de Caso. Rio de Janeiro, 2008. 119p. Dissertação de Mestrado - Departamento de Administração, Pontifícia Universidade Católica do Rio de Janeiro.

O presente trabalho realizou investigações sobre o Projeto de Economia de Comunhão (EdC) buscando compreender e descrever características da dinâmica dos fenômenos poder e decisão em organizações vinculadas a essa proposta. $\mathrm{O}$ tema é significativamente relevante na medida que são apresentadas evidências na literatura organizacional de práticas manipuladoras e opressoras provenientes de uma racionalidade excessivamente instrumental utilizada em larga escala na maioria das organizações. Por outro lado, existe uma lacuna na pesquisa realizada até então sobre EdC no que tange a tais fenômenos. Por meio do método de análise de conteúdo, investigou-se com empresários importantes para o projeto, durante o Congresso Nacional de EdC, os conceitos sustentadores dessas variáveis organizacionais e realizou-se um estudo de caso na empresa Prodiet Farmacêutica visando a um entendimento prático dos mesmos. Notou-se que existem características diferenciadas provenientes, em grande parte, da inversão de valores que os princípios do Projeto impõem em contraponto com o dualismo capital $\mathrm{x}$ trabalho, que o sistema capitalista mais disseminado promove. E, aceitando que as ontologias desses fenômenos os tornam compreensíveis, principalmente, por meio de relações, conclui-se que a significativa contribuição do Projeto é a de construção de interações mais próximas às necessidades humanas, e que, não por acaso, também possibilitam o desenvolvimento e participação competitiva no mercado.

\section{Palavras-chave}

Poder; Decisão; Economia da Comunhão 


\section{Abstract}

SILVA, Guido Vaz. Poder e Decisão em Empresas de Economia de Comunhão: Um Estudo de Caso. Rio de Janeiro, 2008. 119p. Dissertação de Mestrado - Departamento de Administração, Pontifícia Universidade Católica do Rio de Janeiro.

The present study realized inquiries about the Economy of Communion Project (EoC) to understand and to describe characteristics of the dynamics of the power and decision in organizations associated to this proposal. The subject is important since there are evidences in the organizational literature of manipulator and oppressor practices proceeding from an excessively instrumental rationality used in wide scale in the majority of the organizations. On the other hand, there is a gap in the research about EoC concerning such phenomenas. By the method of content analysis, the lifting concepts of these organizational variables were investigated with important entrepreneurs for the project during the National Congress of EdC and with a case study in the Prodiet Farmacêutica to understand the practical agreement of the same ones. It was noticed that they have different characteristics caused by the inversion of values that the principles of the Project impose in counterpoint with dualism between capital and labor that the spread capitalist system promotes. Accepting that the ontologies of these phenomenas make them understandable mainly by means of relations, it can be concluded that the significant contribution of the Project is the construction of interactions closer to the human necessities, and that, not by chance, also allow the development and competitive participation in the market.

\section{Keywords}

Power; Decision; Economy of Communion 


\section{Sumário}

1 O Problema 12

1.1. Introdução 12

$\begin{array}{ll}\text { 1.2. Objetivos } & 16\end{array}$

1.2.1. Objetivo Principal 16

1.2.2. Objetivo Secundário 16

1.3. Delimitações do Estudo 16

1.4. Relevância do Estudo 17

2 Metodologia 19

2.1. Tipo de Pesquisa 19

2.2. Descrição do Método 19

2.3. Coleta de Dados 20

2.4. Unidade de Análise 20

2.5. Tratamento dos Dados $\quad 21$

2.6. Limitações do Método 23

3 Referencial Teórico 25

3.1. O Movimento dos Focolares e a Economia de Comunhão 25

3.2. Decisões e Poder em EdC 28

3.3. Poder 30

3.3.1. Burocracia e Poder 32

3.3.2. Poder segundo Foucault $\quad 34$

3.3.2.1. Resistência e Poder 37

3.3.3. A Dialética do Poder 39

3.4. Decisão 43

3.4.1. Tipologia das Decisões 46

3.4.2. Racionalidade e Decisão 48

3.4.3. Aspectos Políticos da Tomada de Decisão 51

3.4.4. Modelos de Processo Decisório (racional, burocrático, político, consensual e anárquico) $\quad 54$

3.4.5. Relações Cognitivas e Afetivas na Decisão 60

3.4.6. A Decisão como Fenômeno Relacional 61

4 Estudo de campo 64 
4.1. Introdução $\quad 64$

4.2. Visão dos dirigentes $\quad 64$

4.2.1. Temática e textos 65

$\begin{array}{ll}\text { 4.2.2. Roteiro das Entrevistas } & 67\end{array}$

4.2.3. Entrevistas - Empresários 68

4.2.3.1. As Categorias - Empresários 69

4.2.3.2. Conclusões Parciais - Empresários 71

4.3. Estudo de Caso: Prodiet $\quad 75$

4.3.1. Trajetória organizacional $\quad 76$

4.3.2. Percepções sobre o ambiente de trabalho 79

4.3.3. Entrevistas - Prodiet 81

4.3.3.1. As Categorias - Prodiet $\quad 81$

4.3.3.2. As Famílias - Prodiet 84

4.3.3.2.1. Poder e Aspectos Burocráticos 84

4.3.3.2.2. Poder e Aspectos Culturais $\quad 87$

4.3.3.2.3. Poder e Aspectos Relacionais $\quad 91$

4.3.3.2.4. Decisão 93

4.3.4. Conclusões Parciais - Prodiet 98

5 Análise dos Resultados $\quad 101$

5.1. Introdução 101

5.2. Similaridades 101

5.3. Peculiaridades 102

6 Conclusão 106

6.1. Ilações finais 106

6.2. Sugestões para novas investigações 109

7 Referências Bibliográficas 111

8 Apêndices $\quad 116$ 


\section{Lista de quadros}

Quadro 1: Modelo Racional 55

Quadro 2: Modelo Burocrático $\quad 56$

Quadro 3: Modelo Político $\quad 57$

Quadro 4: Modelo Consensual $\quad 58$

Quadro 5: Modelo Anarquia Organizada 59

Quadro 6: Perfil dos empresários $\quad 68$

Quadro 7: Quantidade de entrevistados que citaram a relação 72

Quadro 8: Perfil dos entrevistados $\quad 81$ 


\section{Lista de figuras}

Figura 1: Etapas do método - Empresários 22

Figura 2: Etapas do método - Prodiet 23

Figura 3: Mapeamento do terreno da pesquisa sobre processos decisórios 46

Figura 4: Modelo de seqüência estrutural da tomada de decisão 55

Figura 5: Representação gráfica da estrutura presente nos roteiros $\quad 67$

Figura 6: Relações entre as categorias identificadas pelas entrevistas com os $\begin{array}{ll}\text { empresários } & 73\end{array}$

Figura 7: Agrupamento das categorias em famílias 98

Figura 8: Rebatimento das famílias do estudo na Prodiet sobre as categorias $\begin{array}{ll}\text { derivadas do estudo com os empresários } & 102\end{array}$

Figura 9: Ações interagindo na dinâmica relacional das categorias e famílias 104 
“A Administração, entendida como dotada de métodos e técnicas próprios ou oriundos de outros campos, não pode permanecer indefinidamente como privilégios de alguns. Ao contrário, precisa ser democratizada, isto é, difundida no tecido social, de modo a ser reinventada enquanto força inovadora e prenunciadora de um mundo novo, justo e igualitário".

Fernando C. Prestes Motta 